\title{
Folate-Linked Lipid-Based Nanoparticles Deliver a NF KB Decoy into Activated Murine Macrophage-Like RAW264.7 Cells
}

\author{
Yoshiyuki Hattori ${ }^{a}$ Makoto Sakaguchi, ${ }^{b}$ and Yoshie Maitani ${ }^{*}, a$ \\ ${ }^{a}$ Institute of Medicinal Chemistry, Hoshi University; 2-4-41 Ebara, Shinagawa-ku, Tokyo 142-8501, Japan: and ${ }^{b}$ AnGes \\ MG, Inc.; 4F, Saito Bio-Incubator, 7-7-15 Saito-asagi, Ibaraki, Osaka 567-0085, Japan. \\ Received March 13, 2006; accepted April 20, 2006; published online April 27, 2006
}

\begin{abstract}
Activated macrophages are the key effector cells in rheumatoid arthritis (RA) and secrete multiple mediators of inflammation including proinflammatory cytokines. We investigated delivery of a nuclear factor kappa $B$ (NF KB) decoy by folate-linked lipid-based nanoparticles (NP-F) into murine macrophages. The expression of folate receptor (FR) in RAW264.7 cells activated by lipopolysaccaride was confirmed by strong expression of FR mRNA, and association of FITC-labeled folate-BSA conjugate. When transfected via NP-F, the NF KB decoy was strongly detected in the cytoplasm, and an inhibitory effect on the translocation of NFKB into the nucleus was observed at $0.03 \mu_{\mathrm{M}}$ of the decoy, suggesting that NP-F effectively delivered the NF $\kappa$ B decoy into the cytoplasm. This information is of value for the design of NF $K B$ decoy carrier systems targeting $F R$ in activated macrophages in gene therapy for autoimmune diseases such as RA.
\end{abstract}

Key words nuclear factor kappa B (NF $\kappa$ B) decoy; folate receptor; folate-linked nanoparticle; macrophage; rheumatoid arthritis

Activated synovial macrophages are present in large numbers in arthritic joints in autoimmune diseases such as rheumatoid arthritis (RA), ${ }^{1)}$ and release many proinflammatory cytokines such as tumor necrosis factor- $\alpha(\mathrm{TNF}-\alpha){ }^{1,2)}$ Nuclear factor kappa B $(\mathrm{NF} \kappa \mathrm{B})$ is a transcription factor which normally resides in the cytoplasm, complexed with an inhibitor, $\mathrm{I} \kappa \mathrm{B}$, in an inactive form. ${ }^{3)}$ Proinflammatory cytokines induce a rapid nuclear translocation of $\mathrm{NF} \kappa \mathrm{B}$ through degradation of $\mathrm{I} \kappa \mathrm{B}$, and $\mathrm{NF} \kappa \mathrm{B}$ interacts with response-associated genes such as TNF- $\alpha$, and activates their transcription. ${ }^{2)}$ The decoy technique can block intracellular signaling pathways using a double-stranded oligonucleotide directed at a cognate sequence of $\mathrm{NF} \kappa \mathrm{B}^{3}{ }^{3}$

Although mannosylated cationic liposomes can deliver genes to macrophages, ${ }^{4,5)}$ the target of the NF $\kappa \mathrm{B}$ decoy is activated macrophages; therefore, activated macrophage-selective gene targeting is of great importance. A functionally active folate receptor (FR)- $\beta$ was detected in activated synovial macrophages, ${ }^{6}$ and was utilized a folate-linked imaging agent ${ }^{7)}$ and FR- $\beta$ antibody conjugates. ${ }^{8)}$ However, gene delivery with folate-linked vectors into activated macrophages has not been reported.

Previously, we reported that folate-linked lipid-based nanoparticles (NP-F) delivered DNA with selectively high transfection efficiency into the FR expressed cells. ${ }^{9)}$ In the present study, we examined the efficiency of the transfection of NP-F into activated murine macrophage-like RAW264.7 cells treated with lipopolysaccaride (LPS) by investigating the intracellular distribution of a NF $\kappa \mathrm{B}$ decoy using confocal microscopy. Furthermore, to examine the ability of the decoy to inhibit the translocation of $\mathrm{NF} \kappa \mathrm{B}$ into the nucleus, the amount of $\mathrm{NF} \kappa \mathrm{B}$ in the nucleus was determined by ELISA after transfection with the NFKB decoy via NP-F.

\section{MATERIALS AND METHODS}

Materials The NF $\kappa \mathrm{B}$ decoy oligonucleotide used in this study is a 20-mer phosphorothioate double-stranded oligonucleotide, 5'-CCTTGAAGGGATTTCCCTCC-3'. LPS from
E. coli 111:B4 was purchased from Wako Pure Chemicals (Osaka, Japan). 3([N-( $N^{\prime}, N^{\prime}$-dimethylaminoethane)-carbamoyl]cholesterol (DC-Chol) was purchased from Sigma Chemical Co. (St. Louis, MO, U.S.A.). Tween 80 was supplied by NOF Co. Ltd. (Tokyo, Japan). All reagents were of analytical grade. DMRIE-C reagent, folate deficientRPMI1640 medium and fetal bovine serum (FBS) were purchased from Invitrogen Co. (Carlsbad, CA, U.S.A.).

Cell Culture RAW 264.7 cells were supplied by Riken Cell Bank (Ibaraki, Japan). The cells were grown in a folatedeficient RPMI-1640 medium supplemented with 10\% heatinactivated FBS and kanamycin $(100 \mu \mathrm{g} / \mathrm{ml})$ at $37^{\circ} \mathrm{C}$ in a $5 \%$ $\mathrm{CO}_{2}$ humidified atmosphere.

RT-PCR Analysis of FR Expression in RAW 264.7 Cells Cells were incubated with or without $100 \mathrm{ng} / \mathrm{ml}$ of LPS in medium for $4 \mathrm{~h}$. Total RNA was isolated from the cells and RT-PCR was performed as described previously. ${ }^{9)}$ For the amplification of mouse FR- $\alpha$, the primers FR- $\alpha$-FW, $5^{\prime}$-AGGACTGAACTTCTCAATGTCTGCATGG- ${ }^{\prime}$, and FR- $\alpha-$ RW, 5'-GCTTGTAGGAGTGACTCCAGATTTCCTC-3', were used. For the amplification of mouse FR- $\beta$, the primers FR- $\beta$-FW, 5'-CAAGCTGCATGACCAGTGTAGTCCATGG$3^{\prime}$, and FR- $\beta$-RW, 5'-ATCTGGATGCAGCGGCCACTCCCTCTGC-3', were used. For the amplification of mouse $\beta$ actin, the primers $\beta$-actin-FW, 5'-ACCCACACTGTGCCCATCTA-3', and $\beta$-actin-RW, 5'-CTGCTTGCTGATCCACATCT-3', were used. The PCR products for FRs and $\beta$ actin were analyzed by $1.5 \%$ agarose gel electrophoresis in a Tris-Borate-EDTA (TBE) buffer. The products were visualized by ethidium bromide staining.

Real time PCR was performed on the corresponding cDNA synthesized from each sample described above. The optimized settings were transferred to real time PCR protocols on iCycler MyiQ detection systems (Bio-Rad Laboratories, Hercules, CA, U.S.A.) and SYBR Green I assay (iQ ${ }^{\mathrm{TM}}$ SYBER Green Supermix, Bio-Rad Laboratories) was used for quantification. Samples were run in triplicate and the expression level of FR- $\alpha$ mRNA was normalized for the amount of $\beta$-actin in the same sample. Difference of 1 cycle 
was calculated as a 2 fold-change in the gene expression.

Association of a FITC-Labeled Folate-Bovine Serum Albumin Conjugate Synthesis of a FITC-labeled folateBSA conjugate (FITC-f-BSA) was carried out as previously described. ${ }^{9)}$ Cells were plated into $35-\mathrm{mm}$ culture dishes, and were treated with $100 \mathrm{ng} / \mathrm{ml}$ of LPS for $4 \mathrm{~h}$ before the experiment. FITC-f-BSA was diluted to $10 \mu \mathrm{M}$ in $1 \mathrm{ml}$ of folate-deficient RPMI medium containing 10\% serum and then incubated with the cells in the presence or absence of $1 \mathrm{~mm}$ folic acid. After $30 \mathrm{~min}$ of incubation, the cells were washed twice with PBS ( $\mathrm{pH} \mathrm{7.4)} \mathrm{to} \mathrm{remove} \mathrm{the} \mathrm{unbound} \mathrm{FITC-f-BSA} \mathrm{and}$ fixed with $10 \%$ formaldehyde in PBS for $15 \mathrm{~min}$ at room temperature. For staining the nucleus, the fixed cells were washed and incubated with $0.5 \mathrm{mg} / \mathrm{ml}$ of RNase in PBS for $10 \mathrm{~min}$ at $37^{\circ} \mathrm{C}$. Subsequently, the cells were washed and incubated with propidium iodide (PI) for $10 \mathrm{~min}$ at room temperature. FITC-f-BSA and PI were visualized with a Radiance 2100 confocal laser scanning microscope (Bio-Rad Laboratories) as previously described. ${ }^{9)}$

Preparation of Folate-Linked Nanoparticles Folatepolyethyleneglycol-distearoylphoshatidylethanolamine (f$\mathrm{PEG}_{2000}$-DSPE, mean molecular weight of PEG: $2000 \mathrm{Da}$ ) was synthesized as previously described. ${ }^{10)} \mathrm{NP}-\mathrm{F}$ was prepared with lipids (DC-Chol: Tween $80:$ f-PEG $_{2000}$-DSPE $=$ $93: 5: 2$, molar ratio $=10: 1.3: 1.3 \mathrm{mg}$ ) in $10 \mathrm{ml}$ of water by a modified ethanol injection method as described previously. ${ }^{9)}$ $\mathrm{NP}-\mathrm{F}$ formed nanoplex of about $200 \mathrm{~nm}$, and even in the presence of serum, maintained its size (about $400 \mathrm{~nm}){ }^{9}{ }^{9}$

Transfection Based on a preliminary assay of the inhibition of NF $\kappa$ B activation, the optimized total concentration of lipid in NP-F and DMRIE-C was determined as $60 \mu \mathrm{g} / \mathrm{ml}$. For the transfection with NP-F, the NF $\kappa \mathrm{B}$ double-stranded decoy was diluted to $20,60,200$ and $2000 \mu \mathrm{M}$, and a singlestranded decoy was diluted to 400 and $4000 \mu \mathrm{M}$ with medium. A complex (NP-F nanoplex) was formed by adding the decoy $(3.6 \mu \mathrm{l}$ of $20,60,200,2000 \mu \mathrm{M}$ double-stranded decoy and 400 and $4000 \mu \mathrm{M}$ single-stranded decoy, respectively) to the NP-F solution $(17.1 \mu \mathrm{l})$, mixing with gentle shaking, and leaving the mixture at room temperature for $15 \mathrm{~min}$. The mixture was added to $3.6 \mathrm{ml}$ of medium, and $1 \mathrm{ml}$ was then added to $1 \mathrm{ml}$ of cell culture in a $35-\mathrm{mm}$ culture dish. The transfection with DMRIE-C was performed according to the manufacturer's instructions.

Intracellular Distribution of the NFKB Decoy Cells were plated into $35-\mathrm{mm}$ culture dishes, and treated with or without $100 \mathrm{ng} / \mathrm{ml}$ of LPS for $2 \mathrm{~h}$ before the experiment. The NP-F nanoplex or DMRIE-C lipoplex was formed with the FITC-labeled NF $\kappa \mathrm{B}$ decoy as described above and then diluted in $3.6 \mathrm{ml}$ of medium. The mixtures $(1 \mathrm{ml})$ were added to $1 \mathrm{ml}$ of cell culture and incubated with the cells for $4 \mathrm{~h}$ in the presence of $100 \mathrm{ng} / \mathrm{ml}$ of LPS. After the incubation, the cells were fixed with $10 \%$ formaldehyde and incubated with PI for staining of the nucleus as described above. Examinations were performed with the confocal laser scanning microscope.

Measurement of the Amount of NFKB in the Nucleus Cells were transfected with either the double- or singlestranded decoy using NP-F or the DMRIE-C reagent, and incubated for $4 \mathrm{~h}$ in the medium without LPS and then treated with $100 \mathrm{ng} / \mathrm{ml}$ of LPS for $1 \mathrm{~h}$. The activation of $\mathrm{p} 65$, a transcription factor of the NFKB family, was analyzed using a
TransAM assay kit according to the manufacturer's directions (Active Motif Europe, Rixensart, Belgium). Briefly, the LPStreated cells were scraped off and centrifuged for $10 \mathrm{~min}$ at $1000 \mathrm{rpm}$. The pellet was suspended in $100 \mu \mathrm{l}$ of hypotonic buffer and $5 \mu \mathrm{l}$ of detergent, and was centrifuged for $30 \mathrm{~s}$ at $14000 \mathrm{~g}$. The pellet was resuspended in $20 \mu \mathrm{l}$ of lysis buffer, incubated for $30 \mathrm{~min}$ at $4{ }^{\circ} \mathrm{C}$, and centrifuged for $10 \mathrm{~min}$ at $14000 \mathrm{~g}$. The supernatant constitutes the cell extract. Cell extract from each sample was diluted 5 times and incubated in 96-well plates coated with the NFKB consensus doublestranded oligonucleotide sequence ( $5^{\prime}$-AGTTGAGGGGACTTTCCCAGGC-3') for $1 \mathrm{~h}$. Bound p65 was detected with rabbit anti-mouse p65 antibody and peroxidase-conjugated anti-rabbit IgG antibody. After a colorimetric reaction, the optical density was read at $450 \mathrm{~nm}$.

Cytotoxicity The cytotoxicity upon transfection using NP-F or DMRIE-C was evaluated with a cell proliferation assay kit (Dojindo, Kumamoto, Japan). Cells were placed in a 24-well plate in the medium containing serum, and were transfected with the double-stranded $\mathrm{NF} \kappa \mathrm{B}$ decoy at 0.1 and $1 \mu \mathrm{M}$ or single-stranded NF $\kappa \mathrm{B}$ decoy at $2 \mu \mathrm{M}$ via NP-F or DMRIE-C. After $24 \mathrm{~h}$ of incubation, the medium was removed, and the cells were treated with a WST-8 (2-(2methoxy-4-nitrophenyl)-3-(4-nitrophenyl)-5-(2,4-disulfophenyl)- $2 H$-tetrazolium, monosodium salt) solution $(20 \mu \mathrm{l})$ in medium containing $10 \%$ FBS $(200 \mu \mathrm{l})$ for $1 \mathrm{~h}$. Cell viability was expressed relative to the absorbance at $450 \mathrm{~nm}$ of untreated cells.

Statistical Analysis The statistical significance of the data was evaluated with the Dunnett test. A $p$ value of 0.05 or less was considered significant.

\section{RESULTS AND DISCUSSION}

One major problem in gene therapy is how to transfect target cells efficiently and specifically. First, to investigate the possibility of a FR-based macrophage-targeting therapy, we examined the expression of FR in RAW264.7 cells. RT-PCR analysis of FR- $\alpha$ and $\beta$ mRNA was done using total RNA from RAW264.7 cells with or without LPS treatment. The unstimulated cells with LPS expressed FR- $\alpha$ mRNA weakly, and FR- $\beta$ mRNA not at all (Fig. 1A). However, RAW264.7 cells activated by LPS strongly expressed the FR- $\alpha$ mRNA, but did not express the FR- $\beta$ mRNA (Fig. 1A). FR- $\alpha$ mRNA was increased about 4-fold in the cells by LPS-treatment (Fig. 1B). This suggested that folic acid could be utilized to target activated RAW264.7 macrophages via FR- $\alpha$. Paulos et $a l$. reported that in human macrophages from healthy individuals, FR- $\beta$ was detected immunologically on the surface, but was found to be functionally inactive. ${ }^{7)}$ They also showed that the FR- $\beta$ on activated cells can bind folate-linked compounds with high affinity. ${ }^{6,7)}$ In our study, we found a difference in the expression of the FR isoforms between human RA macrophages and murine RAW264.7 cells. The differences between human primary and murine macrophage-like cell lines can not be compared directly, but it is possible that FR has important roles in the activation of macrophages.

To examine the selectivity of the folate moiety in the uptake into RAW264.7 cells, the intracellular distribution of FITC-f-BSA was visualized by confocal microscopy. The NP-F nanoplex had a positive $\zeta$-potential (about 30- 
A

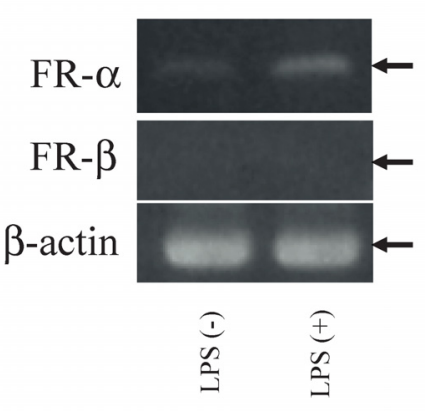

Folate-BSA

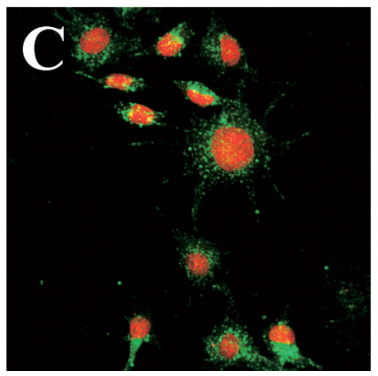

Fig. 1. (A) FR- $\alpha$, FR- $\beta$ and $\beta$-Actin mRNA Expression was Detected in RAW264.7 Cells with or without LPS Treatment by RT-PCR and (B) Relative Amount of FR- $\alpha$ mRNA in the Cells with or without LPS Treatment was Compared by an SYBR Green I-Based Quantitative PCR Analysis

The $y$-axis indicated the fold induction of gene expression. The expression level of FR- $\alpha$ mRNA was normalized for the amount of $\beta$-actin in the same sample. Each result represents the mean \pm S.D. $(n=3) . * * p<0.01$, compared with LPS $(-)$.

(C and D) Association of FITC-f-BSA with RAW264.7 Cells

Cells were treated with $100 \mathrm{ng} / \mathrm{ml}$ of LPS for $4 \mathrm{~h}$. After the treatment, FITC-f-BSA was incubated with the cells for $30 \mathrm{~min}$ in the absence (C) or presence (D) of $1 \mathrm{~mm}$ free folic acid. The FITC-f-BSA was visualized by confocal microscopy (magnification $\times 600$ ). The red signals show the location of the nucleus, and the green signals, that of the FITC-f-BSA. Scale bar $=50 \mu \mathrm{m}$.

$40 \mathrm{mV}){ }^{9)}$ It was reported that a negatively charged folic acid formed a charge-mediated complex with positively charged particles through its carboxyl groups and increased nonspecifically the efficiency of transfection. ${ }^{11)}$ In NP-F, we observed that the addition of folic acid into culture medium decreased non-specifically the efficiency of transfection by interaction between positively charged NP-F and folic acid (data not shown). Therefore, we prepared FITC-f-BSA and incubated it with LPS-stimulated or unstimulated RAW264.7 cells in the absence or presence of $1 \mathrm{~mm}$ folic acid. The amount of FICT-f-BSA associated with the cells increased on LPS treatment (data not shown). The presence of $1 \mathrm{~mm}$ folic acid caused a significant decrease in the amount of FICT-fBSA associated with the LPS-stimulated cells (Figs. 1C, D). These results indicated that the folate moiety promoted the association of FITC-f-BSA with LPS-stimulated RAW264.7 cells, suggesting that FR can be utilized for targeting activated macrophages.

Next, we examined the localization of the FITC-labeled $\mathrm{NF} \kappa \mathrm{B}$ decoy after transfection via NP-F into RAW264.7 cells. In the unstimulated cells, the FITC-signal was moderately strong in the cytoplasm of a few cells (Fig. 2A). In the LPS-stimulated cells, it was detected throughout the cytoplasm strongly and diffusively in most of the cells (Fig. 2B). This might suggest that the FITC-labeled NFKB decoy
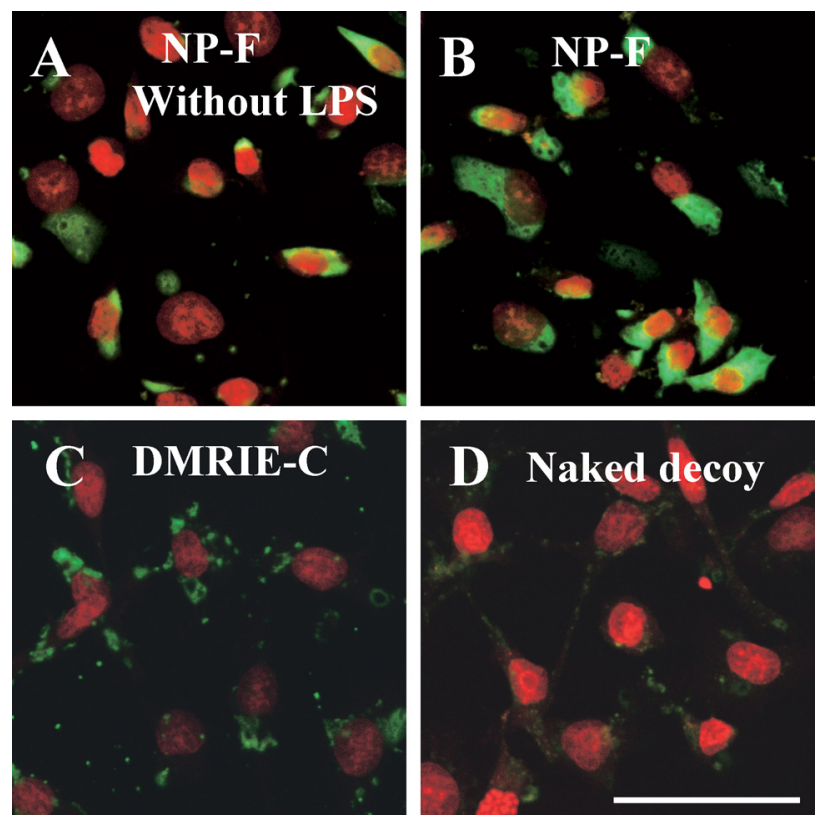

Fig. 2. Comparison of the Intracellular Distribution of the FITC-Labeled NF $\kappa$ B Decoy between NP-F and DMRIE-C Transfection

In (A), RAW264.7 cells were transfected with NP-F nanoplex of $0.1 \mu \mathrm{M}$ NF $\kappa$ B decoy and incubated for $4 \mathrm{~h}$ without LPS. In (B) - (D), the cells were pretreated with $100 \mathrm{ng} / \mathrm{ml}$ of LPS for $2 \mathrm{~h}$. After the pretreatment, the cells were transfected with NP-F nanoplex of $0.1 \mu \mathrm{M} N F \kappa$ B decoy (B), DMRIE-C lipoplex of $0.1 \mu \mathrm{M} N F \kappa \mathrm{B}$ decoy (C), and $1 \mu \mathrm{M}$ naked NF $\kappa \mathrm{B}$ decoy (D), respectively, and incubated for $4 \mathrm{~h}$ in the presence of LPS. The FITC-labeled NF $\kappa$ B decoy was visualized by confocal microscopy (magnification $\times 1200$ ). The red signals show the location of the nucleus, and the green signals, that of the FITC-labeled NF $\kappa$ B decoy. Scale bar $=50 \mu \mathrm{m}$.

nanoplex was efficiently delivered into the cells, was released from the nanoplex, and diffused into the cytoplasm. These results suggested that the association of the FITC-labeled $\mathrm{NF} \kappa \mathrm{B}$ decoy with the activated macrophages occurred via FR and that NP-F was able to deliver the decoy into the cytoplasm of activated macrophages. This in vitro distribution of the NF $\kappa \mathrm{B}$ decoy observed in RAW 264.7 cells agreed with that reported by Higuchi et al., showing that most of the fluorescent-labeled NF $\kappa \mathrm{B}$ decoy was observed in the cytoplasm when transfected by cationic liposomes into RAW264.7 cells stimulated with LPS. ${ }^{12)}$ DMRIE-C reagent is a liposomal formulation of the cationic lipid DMRIE composed of 1,2dimyristyloxypropyl-3-dimethyl-hydroxy ethyl ammonium bromide and cholesterol at $1: 1(\mathrm{M} / \mathrm{M})$. It is known to be suitable for the transfection of DNA into suspended cells and other lymphoid-derived cell lines. When the ability to carry genes into LPS-stimulated RAW264.7 cells was compared between NP-F and the DMRIE-C reagent, the intracellular distribution of the FITC-labeled NF $\kappa \mathrm{B}$ decoy transfected with DMRIE-C was much weaker than that obtained with NP-F in the cytoplasm (Fig. 2C). In the case of the naked $\mathrm{NF} \kappa \mathrm{B}$ decoy, little intracellular localization was observed in the cells (Fig. 2D).

To examine the ability of the decoy to inhibit the translocation of $\mathrm{NF} \kappa \mathrm{B}$ into the nucleus after the stimulation by LPS, the amount of NFKB in the nucleus was determined by ELISA after transfection with the NF $\kappa \mathrm{B}$ decoy via either NP-F or the DMRIE-C reagent. Following LPS treatment, the amount of NF $\kappa \mathrm{B}$ in the nucleus was greater when the single-stranded decoy as a control was transfected by either NPF or DMRIE-C into the cells (Fig. 3A), suggesting that this 
A

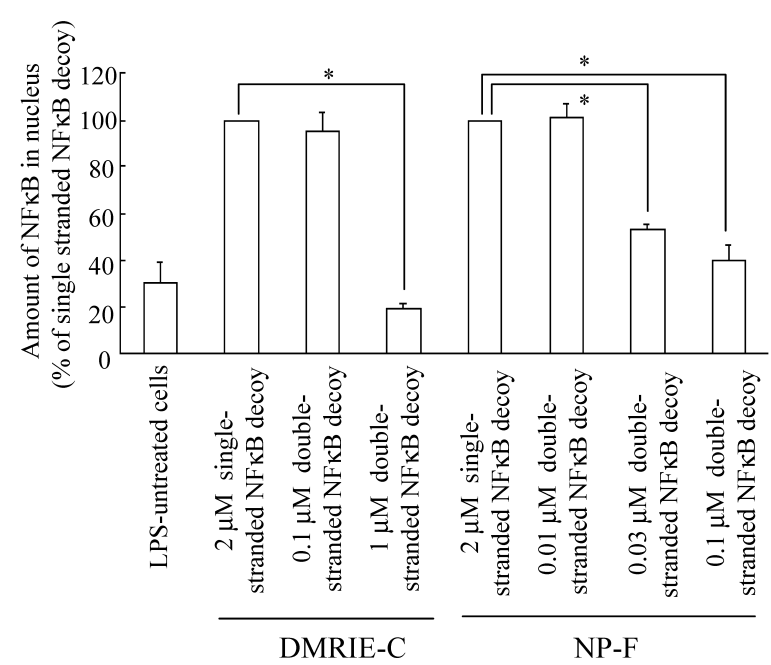

B

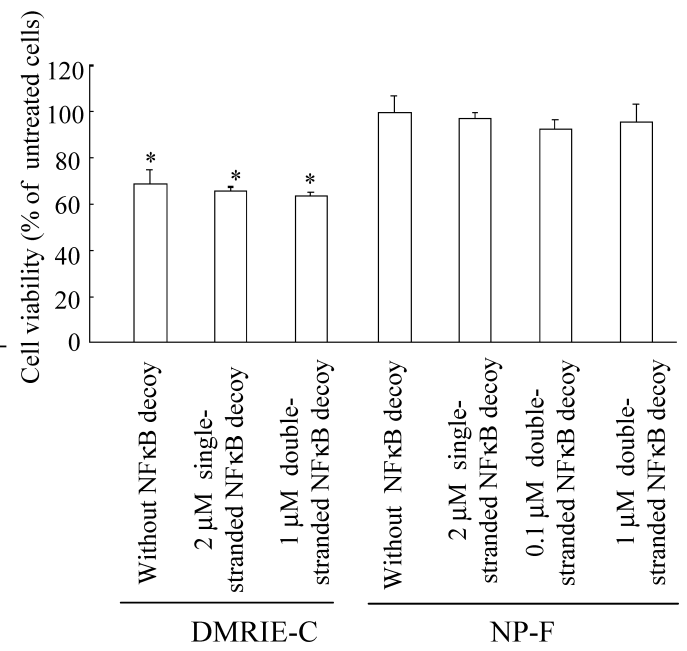

Fig. 3. (A) Inhibition of the Translocation of NF $\kappa$ B in LPS-Treated RAW264.7 Cells by the NF $\kappa$ B Decoy Transfected by NP-F or DMRIE-C Reagent Cells were incubated with NP-F nanoplex or DMRIE-C lipoplex of either single- or double-stranded decoy for $4 \mathrm{~h}$ and then treated with $100 \mathrm{ng} / \mathrm{ml}$ of LPS for $1 \mathrm{~h}$.

(B) Cytotoxicity of NP-F Nanoplex and DMRIE-C Lipoplex of NF $\kappa$ B Decoy

Each result represents the mean \pm S.D. $(n=3)$. Statistically significant difference $(* p<0.05)$ from untransfected cells.

decoy could not inhibit the translocation of NF $\kappa$ B. The double-stranded NF $\kappa \mathrm{B}$ decoy transfected by DMRIE-C did not inhibit the translocation of $\mathrm{NF} \kappa \mathrm{B}$ even at $0.1 \mu \mathrm{M}$, however, it well inhibited it at $1 \mu \mathrm{M}$. The double-stranded NF $\kappa \mathrm{B}$ decoy transfected by NP-F, inhibited the translocation of NF $\kappa \mathrm{B}$ at 0.03 and $0.1 \mu \mathrm{M}$, indicating that NP-F could achieve the same degree of inhibition at a 10 times lower concentration of decoy. The cellular uptake of the NFKB decoy was much greater with NP-F than the DMRIE-C reagent (Fig. 2); therefore, the inhibition of NFKB's translocation into the nucleus may be more effective than that obtained with DMRIE-C.

Finally, we investigated the cytotoxicity of the transfection by NP-F or the DMRIE-C reagent. Either the NP-F nanoplex or DMRIE-C lipoplex was formed at various concentrations of the NFKB decoy $(0.1$ and $1 \mu \mathrm{M})$, and the cytotoxity was assessed by the WST- 8 assay after incubation of the cells with the nanoplex or lipoplex in the medium with serum for $24 \mathrm{~h}$. No cytotoxicity was observed without the NFKB decoy using NP-F. However, significant toxicity was observed using DMRIE-C compared with untransfected cells (Fig. 3B). When the cells were transfected with the NP-F nanoplex containing 0.1 and $1 \mu \mathrm{M}$ double-stranded NF $\kappa \mathrm{B}$ decoy or $2 \mu \mathrm{M}$ single-stranded NF $\kappa \mathrm{B}$, no cytotoxicity was observed (Fig. 3B). A liposomal formulation containing DC-Chol has been administered to patients in clinical trials for treating cancer because of its strong transfection activity and low toxicity. ${ }^{13}$ ) The DC-Chol-based folate-linked nanoparticle used in this study showed little cytotoxicity in RAW264.7 cells (Fig. 3B). It will be important to develop applications in vivo.

Antohe et al. reported that systemically administered folate-fluorescent conjugates accumulated in protrusions of atherosclerotic plaques populated by macrophages, suggesting that activated macrophages can be efficiently targeted in vivo by using a folate conjugate. ${ }^{14)}$ Paulos et al. reported that folate-linked imaging agents could be selectively delivered to arthritic joints, allowing the visualization of RA. ${ }^{7)}$ These reports suggested that a folate-linked therapeutic agent could be selectively delivered to activated macrophages in vivo, allowing the treatment of RA. We also confirmed that the folate moiety promoted the association of FITC-f-BSA with RAW264.7 cells treated with LPS (Figs. 1C, D). Therefore, the FR expression and folic acid can be utilized to target activated macrophages in humans and mice.

In conclusion, we have demonstrated that NP-F effectively delivered a NF $\kappa \mathrm{B}$ decoy into the cytoplasm, which inhibited the translocation of NF $\kappa \mathrm{B}$ into the nucleus of LPS-activated macrophages, compared with commercial transfection reagent, DMRIE-C. To our knowledge, this is the first report that folate-linked vector is effective for DNA delivery into activated macrophage-targeting. This information is of value for the design of carriers for NF $\kappa \mathrm{B}$ decoys that will enable therapy for rheumatoid arthritis to be carried out.

Acknowledgments We thank Dr. Kazuhiro Kubo (NOF Corporation, Tokyo, Japan) for supplying amino-PEG-DSPE. This project was supported in part by a grant from the Promotion and Mutual Aid Corporation for Private Schools of Japan, and by a Grant-in-Aid for Scientific Research from the Ministry of Education, Culture, Sports, Science, and Technology of Japan.

\section{REFERENCES}

1) Kinne R. W., Brauer R., Stuhlmuller B., Palombo-Kinne E., Burmester G. R., Arthritis Res., 2, 189-202 (2000).

2) Blackwell T. S., Christman J. W., Am. J. Respir. Cell Mol. Biol., 17, 3-9 (1997).

3) Morishita R., Tomita N., Kaneda Y., Ogihara T., Curr. Opin. Pharmacol., 4, 139-146 (2004).

4) Kawakami S., Sato A., Nishikawa M., Yamashita F., Hashida M., Gene Ther., 7, 292-299 (2000).

5) Kawakami S., Hattori Y., Lu Y., Higuchi Y., Yamashita F., Hashida M., Pharmazie, 59, 405-408 (2004).

6) Nakashima-Matsushita N., Homma T., Yu S., Matsuda T., Sunahara N., Nakamura T., Tsukano M., Ratnam M., Matsuyama T., Arthritis Rheum., 42, 1609-1616(1999). 
7) Paulos C. M., Turk M. J., Breur G. J., Low P. S., Adv. Drug Deliv. Rev., 56, 1205-1217 (2004).

8) Nagayoshi R., Nagai T., Matsushita K., Sato K., Sunahara N., Matsuda T., Nakamura T., Komiya S., Onda M., Matsuyama T., Arthritis Rheum., 52, 2666-2675 (2005).

9) Hattori Y., Maitani Y., Cancer Gene Ther, 12, 796-809 (2005).

10) Hattori Y., Maitani Y., J. Control Release, 97, 173-183 (2004).

11) Guo W., Lee R. J., J. Control Release, 77, 131-138 (2001).
12) Higuchi Y., Kawakami S., Nishikawa M., Yamashita F., Hashida M., J. Control Release, 107, 373-382 (2005).

13) Nabel G. J., Nabel E. G., Yang Z. Y., Fox B. A., Plautz G. E., Gao X., Huang L., Shu S., Gordon D., Chang A. E., Proc. Natl. Acad. Sci. U.S.A., 90, 11307-11311 (1993).

14) Antohe F., Radulescu L., Puchianu E., Kennedy M. D., Low P. S., Simionescu M., Cell Tissue Res., 320, 277-285 (2005). 